\title{
Experimental performance comparison between circular and elliptical tubes in evaporative condensers
}

\author{
Giuseppe Starace $^{1} \cdot$ Lorenzo Falcicchia $^{2} \cdot$ Pierpaolo Panico $^{2} \cdot$ Maria Fiorentino $^{2} \cdot$ Gianpiero Colangelo $^{2}(\mathbb{D}$
}

Received: 19 October 2020 / Accepted: 28 June 2021 / Published online: 10 July 2021

(C) The Author(s) 2021

\begin{abstract}
In refrigeration systems, evaporative condensers have two main advantages compared to other condensation heat exchangers: They operate at lower condensation temperature than traditional air-cooled condensers and require a lower quantity of water and pumping power compared to evaporative towers. The heat and mass transfer that occur on tube batteries are difficult to study. The aim of this work is to apply an experimental approach to investigate the performance of an evaporative condenser on a reduced scale by means of a test bench, consisting of a transparent duct with a rectangular test section in which electric heaters, inside elliptical pipes (major axis $32 \mathrm{~mm}$, minor axis $23 \mathrm{~mm}$ ), simulate the presence of the refrigerant during condensation. By keeping the water conditions fixed and constant, the operating conditions of the air and the inclination of the heat transfer geometry were varied, and this allowed to carry out a sensitivity analysis, depending on some of the main parameters that influence the thermo-fluid dynamic phenomena, as well as a performance comparison. The results showed that the heat transfer increases with the tube surface exposed directly to the air as a result of the increase in their inclination, that has been varied in the range $0-20^{\circ}$. For the investigated conditions, the average increase, resulting by the inclination, is $28 \%$.
\end{abstract}

Keywords Evaporative condenser · Heat transfer $\cdot$ Refrigeration · Circular tubes $\cdot$ Elliptical tube $\cdot$ Heat exchanger

$\begin{array}{ll}\text { Abbreviations } \\ \text { AHU } & \text { Air handling unit } \\ \text { COP } & \text { Coefficient of performance }(-) \\ \dot{G} & \text { Volumetric flowrate }\left(\mathrm{m}^{3} \mathrm{~h}^{-1}\right) \\ i & \text { Specific enthalpy }\left(\mathrm{Jg}^{-1}\right) \\ \dot{m} & \text { Mass flowrate }\left(\mathrm{kg} \mathrm{s}^{-1}\right) \\ \mathrm{p} & \text { Pressure }(\mathrm{Pa}) \\ \mathrm{PID} & \text { Proportional-integral-derivative } \\ \dot{Q} & \text { Heat power }(\mathrm{W}) \\ \mathrm{R} & \text { Perfect gas constant }\left(\mathrm{J} \mathrm{kg}^{-1} \mathrm{~K}^{-1}\right) \\ \mathrm{RH} & \text { Relative humidity }(\%) \\ \mathrm{RTD} & \text { Resistance temperature detector } \\ \mathrm{T} & \text { Temperature }\left({ }^{\circ} \mathrm{C}\right) \\ \mathrm{x} & \text { Absolute humidity }(-) \\ \phi & \text { Vapor pressure ratio } \\ \rho & \text { Density }\left(\mathrm{kg} \mathrm{m} \mathrm{m}^{-3}\right)\end{array}$

Gianpiero Colangelo

gianpiero.colangelo@unisalento.it

1 Department of Management, Finance and Technology, University LUM, 70010 Casamassima (Ba), Italy

2 Department of Engineering for Innovation, University of Salento, 73100 Lecce, Italy

\begin{tabular}{ll}
\multicolumn{2}{l}{ Subscripts } \\
air & Air \\
amb & Ambient \\
da & Dry air \\
db & Dry bulb \\
evap & Evaporated \\
s & Surface \\
sat & Saturation
\end{tabular}

\section{Introduction}

The growing interest in the optimization and improving of refrigeration systems [1-3] is one of the main topics in this field, because of the great impact that these systems have on the global energy demand and environmental impact.

Ahmadi et al. [1] carried out an optimization analysis of an Ericsson cryogenic refrigerator system. In particular, they focused their investigation on the optimization of ecological and thermal performance for different settings using three objective functions: input power; $\mathrm{COP}$; and ecological objective function. They used evolutionary algorithm and thermodynamic analysis to elaborate the optimum points of the input power, COP and ecological objective function of the system, exploring four different configurations. The 
results obtained by their optimization were shown by using a Pareto font with the possible optimal points. In this way, they used a process of decision-making for choosing the ultimate optimum result in the space of the objectives of the research in particular they included, as important parameters for optimal decision, effectiveness of the hot-side heat exchanger, effectiveness of the cold-side heat exchanger and temperature of cold side.

In another paper, Ahmadi et al. [2] studied the assessment indexes for irreversible refrigeration cycles to identify the ecological and exergetic performance coefficient for irreversible Carnot refrigeration cycle including all the irreversibility parameters in their analysis. Their work showed the results for two hypotheses: optimization of ecological coefficient of performance and exergy input and cooling load by means of multi-objective optimization algorithms; while in the second hypothesis, they used three objective functions, including ecological coefficient of performance, exergy input and exergy performance criteria, with a multiobjective optimization algorithm. In particular, their study showed the importance of the effectiveness of the condenser and the effectiveness of the evaporator in the evaluation of exergy input to the system.

An interesting application was investigated by Mohammadi et al. [3]. In their work, they carried out a thermodynamic analysis on a small hybrid system that combined a gas turbine with an ORC cycle and an absorption refrigeration cycle for the combined production of cooling, heating and electricity. They used a parametric analysis to investigate the effect of different parameters on the system performance and output cooling, heating and power. Their results showed, in particular, that minimum and maximum pressure of refrigeration system along with heat exchangers effectiveness influenced energy efficiency of the plant and COP of refrigeration system.

Due to their higher heat transfer coefficients per unit area, lower condensing temperature, reduced water consumption and pumping power, the evaporative condensers are characterized by better performance and lower operation costs, compared to dry condensing units and water condensers related to cooling towers. Actually, they operate at lower condensing temperature, leading to a higher COP.

The advantages of the evaporative cooling have been investigated by many researchers. Bykov [4] proposed a method able of calculating the variation in water and air operating conditions in three different condenser zones. Webb [5] developed a unified theory for evaporative towers. Qureshi and Zubair evaluated the effects of fouling $[6,7]$ and, subsequently, the influence of condensation temperature and relative humidity of the inlet air on the heat dissipation capability. Through CFD analysis, Acunha and Schneider [8] simulated the air and water flows in an evaporative condenser, while Jahangeer [9] presented a numerical model valid for a single pipe, with water and air in cross-flow configuration, assuming a constant surface temperature and solving the equations through the finite differences method. Rashidi et al. [10] summarized the experimental and numerical studies performed to evaluate the effects of using nanofluids as heat transfer fluids in condensing and evaporating systems. They studied the advantages and disadvantages of this kind of heat transfer fluids in condensing and evaporating systems. Fiorentino and Starace [11] evaluated the effects of the condensing temperature and of the inlet air conditions on the global heat transfer coefficient, by carrying out a 2D numerical analysis on a heat transfer domain consisting of a portion of fluid between two not-aligned tubes and then analyzing the type of water flow regime established around the tubes varying the water-air ratio and their spatial arrangement [12]. In order to validate a mathematical model [13] that simulated the operation of the evaporative condenser in steady-state conditions, Leidenfrost and Korenic have experimentally evaluated the behavior of the system at the variation in water, air and refrigerant flowrate [14]. Nasr and Hassan [15] have designed an innovative evaporative condenser for small refrigeration systems and have studied its performance through experimental tests. Tissot [16] evaluated the increase in COP due to the use of evaporative cooling, spraying water on the surface of a dry condensing unit. Islam [17] carried out an experimental campaign about the air conditioning systems operating with an evaporative condenser, creating a theoretical model, valid for a small tube segment, in good agreement with the experimental data. Ettouney [18] experimentally evaluated the performance of an evaporative condenser as the water-air ratio varied and obtained empirical mathematical functions for the heat transfer coefficients. Hajidavalloo and Eghtedari [19] compared two air conditioning systems operating with evaporative and dry condensed units, while Liu [20] analyzed the performance, the heat transfer coefficient and the COP of an air conditioning system, varying the compressor electric supply frequency, dry bulb temperature, air velocity and water flow rate. Junior and Smith-Schneider [21] carried out an experimental analysis on a small-scale evaporative condenser, obtaining empirical equations to predict the heat dissipation as a function of water and coolant temperatures, dry and wet bulb air temperature and water-to-air flow ratio; this analysis was carried out without any control over air conditions.

Recently, Brodnianská and Kotšmíd [22] have studied numerically the heat transfer from a heated cylinder and tube arrays to obtain the local and average Nusselt numbers. The heated tubes have been arranged in arrays $4 \times 1$ and $4 \times 2$ with the tube ratio spacing SV/D $=2$. The obtained Nusselt numbers have been compared with the existing equations to find a good agreement. Their results showed that the Nusselt 
numbers increase with the Rayleigh numbers and tube spacing increasing.

Adam et al. [23] published a review where they summarized fin-and-tube heat exchangers thermal performance and flow. Their review critically examined the major configuration, geometry and material type effects on thermal-hydraulic performance with a particular attention to elliptical cross section geometry. In their work, they made a summary of both the theoretical and experimental studies on elliptical tube heat exchangers performance with reference to the effects of tubes dimension, arrangement and number of rows.

One of the first work about evaporators with elliptical tubes is that by Moalem and Sideman [24]. In this work, they studied the characteristics of the various parameters affecting the films and overall heat transfer coefficients of horizontal evaporator-condenser elliptical tubes. Their investigations were focused on the effects of the axis ratio of the tube.

Zhang et al. [25] carried out an experimental campaign to investigate the heat transfer behavior of horizontal twisted elliptical tubes, operating with condensing steam. The experimental tests were carried out at temperature of $100.5^{\circ} \mathrm{C}$. The results indicated that heat transfer coefficients reduced with the increase in wall subcooling, while the enhancement factor of each elliptical tube was constant with an average enhancement in the range from 0.87 to 1.34 . The heat transfer coefficients increased with the rise of the tubes ellipticities, in particular, they obtained an increase of $34 \%$ for the elliptical tube with the largest ellipticity of 0.86 .

Janjua et al. [26] studied, with the use of the software Fluent, the thermal behavior of isothermal horizontal cylinder with different cross sections: circular, elliptical, square, rectangular, hexagonal and triangular. They considered different angles of attack (from $0^{\circ}$ to $90^{\circ}$ ) for elliptic cross section. Their work showed that the Nusselt number depends on the Reynolds number, as well as the orientation of the elliptical tube, confirming experimental results.

Yang and Chen [27] studied an analytical solution for transient laminar film condensation on a horizontal elliptical tube.

Indurain et al. [28] carried out numerical simulations using OpenFOAM to investigate the capability of swirling flow of several geometries of short-length twisted tube with non-circular cross section. They found that a short-length twisted tube with an elliptical cross section was able to generate a swirling flow, and its intensity depended on its twist pitch and its aspect ratio: The lower the aspect ratio, the higher the intensity.

The study of Sharma et al. [29] was about the influence of cross section geometry on microchannels heat transfer performance with single-phase and multi-phase fluid flow. In particular, their study focused on the thermal and hydraulic characteristics of fluid flow in microchannels at different hydraulic diameters including the effects of Reynolds and Nusselt number, friction factor, pressure drop, working fluid and cross section geometry of duct, as well as the hydrodynamic and thermal aspects. They found that transition from laminar to turbulent was influenced by channel cross section geometry, aspect ratio and roughness. They found by exploring literature that researchers only explored the laminar region in their studies, while the turbulent flow regime is yet to be studied deeply.

The experimental work carried out by Aghayari et al. [30], instead, showed the performance obtained using a water-based nanofluid in a double-pipe heat exchanger with twisted-tape inserts. In their investigation, carried out in turbulent regime, they observed different parameters: mass flowrate; twist ratio of tape; temperature; and volumetric concentration of the nanofluid. Their results showed that twisted-tape inserts increased heat transfer and Nusselt number in the range of the investigated flow regimes with no evident change in friction factor.

Payambarpour et al. in their works [31, 32] investigated the behavior of heat and mass transfer in heat exchangers under wet-surface condition using equations of energy balance on a repetitive fin of the heat exchanger two-dimensionally obtaining fin efficiency and temperature distribution in different scenarios using two patterns and three percentages of wetness. The results showed that an increase in the percentage of fin wetness area leaded to a decrease in efficiency since the temperature gradient increases and that fin percentage of wetness influenced the fin efficiency.

Fiorentino and Starace [33-38] have designed and built a test bench that allows to measure and control all the parameters that affect the heat dissipation capabilities of an evaporative condenser, also allowing a comparison between different heat transfer geometries. They investigated the influence, on the dissipated heat power, of relative humidity and dry bulb temperature of the air, the temperature and flowrate of the water [34], the combined effect of dry bulb temperature and relative humidity at the same wet bulb temperature of the air [35]. Further studies have been carried out in order to evaluate the influence of the condensing temperature, air flowrate and different transverse pitch between the exchange geometry [36] on the performance of the system. Based on their results, a regression model was elaborated to allow the prediction of the air conditions after passing through a single pipe rank, according to the investigated input variables, and with it an iterative algorithm that allows to obtain the curve of the air conditions for a greater number of ranks [38]. The totality of these studies [33-38] investigated tubes with circular section as heat transfer geometry. The possibility that the test bench used for this investigation offers, to use different exchange geometries, allows to analyze the influence on the performance with the variation in the same geometries. An elliptical section geometry has been adopted 
for this work. This choice has been suggested by the analysis of the cited literature and by the need of optimizing the heat transfer phenomenon in the refrigeration systems in order to reduce energy consumptions, increasing energy efficiency. The potential possible engineering applications of this geometry is not limited only to evaporative condensers of refrigeration systems, but to other kinds of heat exchangers as well: cross-flow heat exchangers as radiators, etc.; shell and tube heat exchangers, used in a wide range of industrial applications and so on. The results of this experimental investigations are not limited only to the specific application the analysis is conceived for, but could be extended to many other engineering applications.

Even if theoretical and numerical studies have been done, the experimental investigation on elliptical tubes is very difficult and complex to carry out, as suggested by the limited experimental works that have been found in the literature about this specific topic so far. Elliptical tubes offer some advantages to be considered in the refrigeration systems, that have to be investigated together with their critical aspects, that the new test rig made possible. General aspects, such as the influence of relative humidity and dry bulb temperature of the air, on the heat power dissipation, as the inclination variations, were first evaluated. Subsequently, a comparison between the results obtained in this work for an elliptical geometry with the results deriving from the use of a circular geometry was performed as well.

\section{Materials and methods}

The scheme of the experimental setup is reported in Fig. 1.

The experimental setup consists of:

- An air handling unit;

- A chiller;

- A heat and mass transfer section;

- The hydraulic circuit.

The air handling unit is used to control the operating conditions of the air in terms of flow rate, dry bulb temperature and relative humidity. The unit consists of an electric heating section with a nominal power of $8 \mathrm{~kW}$, a $3 \mathrm{~kW}$ water-cooled coil and a high-efficiency evaporating pack heat exchanger. The cooling water is sent to a $4 \mathrm{~kW}$ air-cooled chiller.

The operating conditions of the air are set by a PID controller (Omron E5CC), placed on the control panel; the actual values are measured by a thermo-hygrometer ( $\mathrm{Sie}$ mens QFM3160D). The fan is equipped with an inverter in order to allow a continuous regulation of the air flowrate. The air is completely recirculated from the heat exchanger section to the air treatment unit.
The core of the test bench is the heat exchanger section. This consists of a rectangular section duct $(450 \times 200 \times 1800$ $\mathrm{mm}^{3}$ ) in which a battery of staggered tubes is housed, as the picture reported in Fig. 2 shows. The phenomenon of refrigerant condensation inside the tubes is simulated by the presence of three electric resistance heaters, placed inside three "active" tubes (Fig. 3), whose temperature is kept constant by means of a feedback circuit, thanks to 3 RTD Pt100 sensors placed inside the active tubes. The close contact between the inner surface of the tubes, in the appropriate housings, and the outer surface of the electric heaters and RTD sensors, ensures that the measured temperatures are actually those reached by the outer surface of the tube. The surface temperature of the tubes can therefore be set by means of the PID controllers on the control panel.

The remaining tubes are used to establish, inside the heat exchanger section, the fluid dynamic conditions similar to those of a real condensing unit.

The water is drawn from the sink at the bottom and delivered, by means of a circulator, at the top above the active pipes. The water temperature is measured through an RTD Pt100, while the flowrate is recorded by an electromagnetic flowmeter and can be regulated either by a three-way valve or by varying the pump speed.

The water level in the sink is controlled by a float valve, which allows the reintegration of the evaporated water.

The actual wet air conditions, before and after the interaction with the battery of pipes, are measured by two thermo-hygrometers.

The experimental tests were carried out in Lecce, in the laboratory named "Progettazione integrata di impianti: sezione di Fisica Tecnica [Applied Thermodynamics Section of the Energy Systems Design Lab]" at the Dept. of Engineering for Innovation of the University of Salento.

The input parameters, set by means of the appropriate PID controllers on the control panel, are:

- Dry bulb temperature and relative humidity at the inlet and outlet sections of the air handling unit;

- Supply air flowrate;

- Flowrate and temperature of the water;

- External surface temperature of the investigated tubes of the heat exchanger.

After the system reaches the steady-state conditions, the output parameters can be measured by means of the two thermo-hygrometers at the inlet and outlet of the test chamber:

- Temperature and humidity of the air upstream of the interaction by the electrical resistors (they differ from those set in the AHU supply, due to the fact that in the vertical channel upstream of the test section, the water 
Fig. 1 Experimental setup (T: Thermo-regulator, TH: Thermohygrometer)
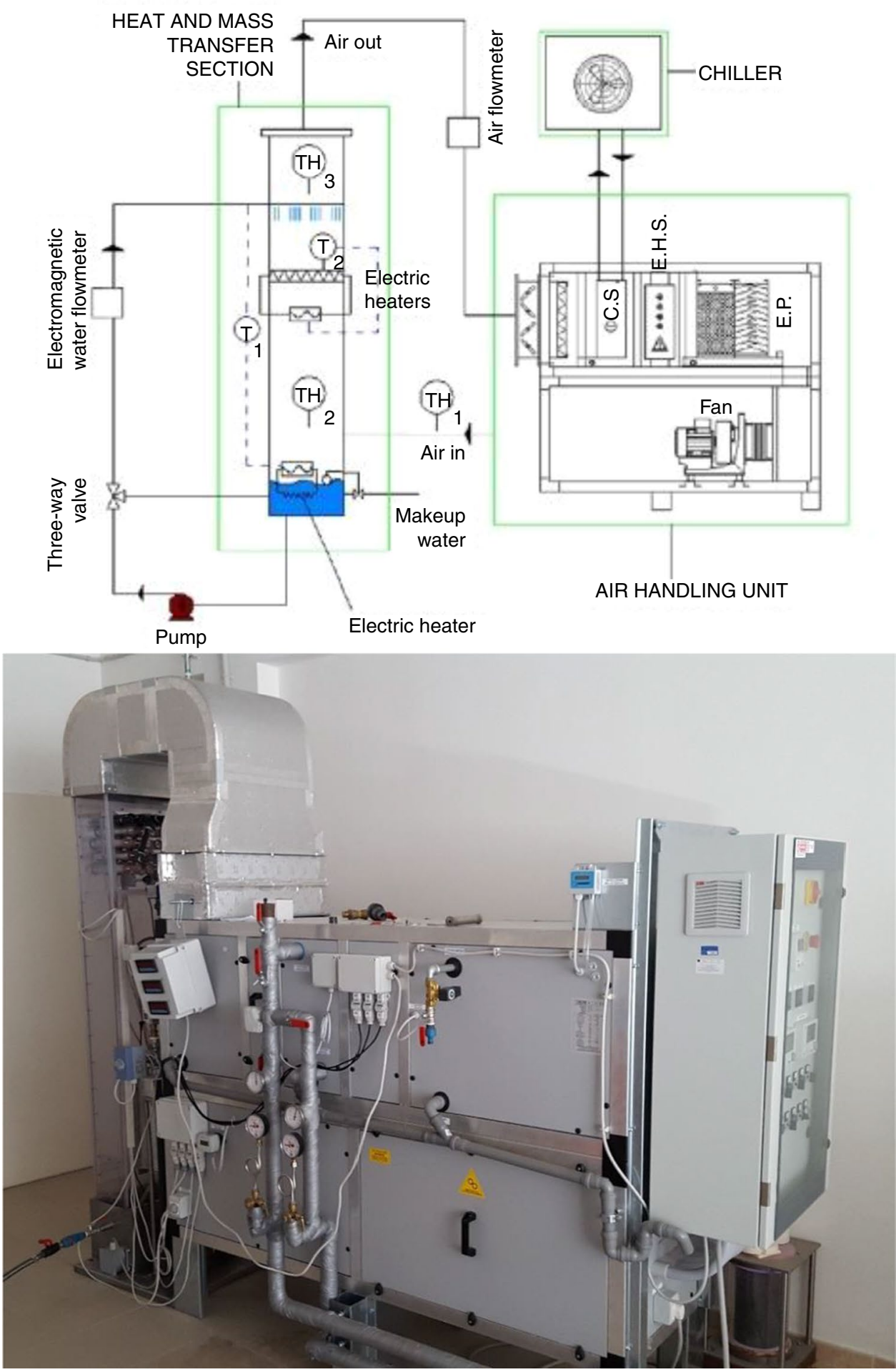

comes into contact with the air and causes cooling and humidification);

- Temperature and humidity of the air after interaction with the electrical resistors. Once temperature and humidity have been recorded, it is possible to determine the heat power transferred by the resistors to the air.
Tests were carried out using circular and elliptical tubes as exchange geometry. On the latter, the tests were carried out by choosing three inclinations (respectively, $0^{\circ}, 10^{\circ}$ and $20^{\circ}$ ) of the elliptical section with respect to the main direction of the air flow. The inclination is the angle between the longer axis of the ellipse and the axis of the test channel and it is obtained by rotating the tubes on their axis. 


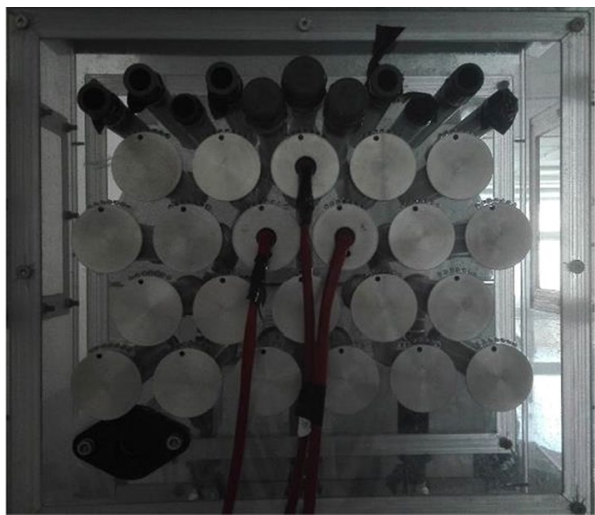

Fig. 2 Staggered tubes setup. Rotating elliptical tubes, the right inclination can be reached (reference pin holes were drilled ad hoc in the transparent wall of the test section)

The tests were used to compare the obtained results with those for tubes with a circular cross section. The latter, if compared with those of the previous campaigns performed both numerically and experimentally on the same test bench [33-36], were taken as a validation of the present results.

The geometrical parameters of the investigated staggered tubes configuration are reported in Table 1.

The heat transfer performance of the pipes with elliptical geometry was used to analyze the dependence on the relative humidity and on the dry bulb temperature of the inlet air, as well as on the inclination of the elliptical section with respect to the main direction of the flow. The inclination was set experimentally using reference pinholes between pipes and plexiglass transparent walls on which they are mounted.

The main characteristics of the instrumentations of the experimental setup, reported in Fig. 1, provided for reading the physical parameters, are reported in Table 2.

The temperature and humidity, obtained as output from the tests, are used to determine the heat power transferred to the air and the mass of evaporated water. The first step is to calculate the saturation pressure useful to calculate the absolute humidity content of the air [39]:

$p_{\text {sat }}=e^{\mathrm{b}}$
Table 1 Main geometrical parameters of the tested tubes

\begin{tabular}{llllll}
\hline Shape/mm & $\begin{array}{l}\text { Major } \\
\text { axis/mm }\end{array}$ & $\begin{array}{l}\text { Minor } \\
\text { axis/mm }\end{array}$ & $\begin{array}{l}\text { Lateral } \\
\text { surface/ } \\
\mathrm{cm}^{2}\end{array}$ & $\begin{array}{l}\text { Equivalent } \\
\text { radius/mm }\end{array}$ & Length \\
\hline Elliptic & 32 & 23 & 156.58 & 13.85 & 180 \\
Circular & 25 & 25 & 141.37 & 12.50 & 180 \\
\hline
\end{tabular}

where $b$ is a coefficient, function of the dry bulb temperature, calculated as follows:

$b=\frac{7066.27}{T_{\mathrm{db}}+273.15}-5.976 \ln \left(T_{\mathrm{db}}+273.15\right)$

The absolute humidity content is calculated by the following equation:

$x_{\text {air }}=0.622 \phi_{\text {air }} \frac{p_{\text {sat }}}{p_{\text {amb }}-\phi_{\text {air }} p_{\text {sat }}}$

The absolute humidity is used to calculate the density of the air, the latter is a function not only of the absolute humidity, but also of the universal constant of the gas $\mathrm{R}$, of the dry bulb temperature $T_{\mathrm{db}}$ and of the ambient pressure $\mathrm{p}_{\mathrm{amb}}$ :

$\rho_{\text {air }}=\frac{0.622 \cdot p_{\mathrm{amb}}}{R_{\mathrm{air}}\left(T_{\mathrm{db}}+273.15\right)\left(0.622+x_{\mathrm{air}}\right)}$

The wet air mass flowrate is obtained by multiplying the volume flow rate $\dot{G}_{\text {air }}$ by the density of the air from the handling unit.

$\dot{m}_{\text {air }}=\dot{G}_{\text {air }} \cdot \rho_{\text {air,setpoint }}$

The mass flowrate of the dry air is:

$\dot{m}_{\mathrm{da}}=\frac{\dot{m}_{\text {air }}}{1+x_{\text {air,setpoint }}}$

The specific enthalpy is a function of the dry bulb temperature and air absolute humidity:

$i_{\text {air }}=1.005 \cdot T_{\mathrm{db}}+x_{\mathrm{air}} \cdot\left(1.9 \cdot T_{\mathrm{db}}+2500\right)$
Fig. 3 Active tube main axis section of an elliptical tube (dimensions in $\mathrm{mm}$ )

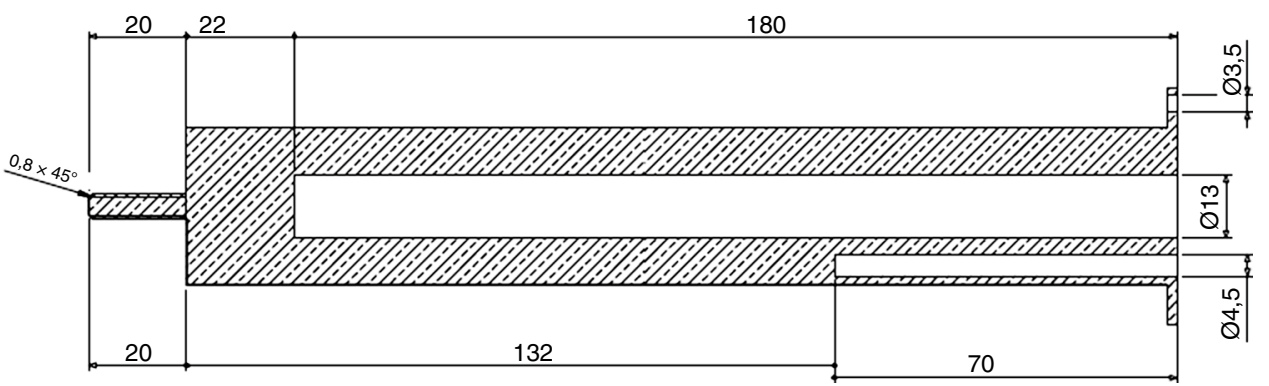


Table 2 Test bench instrumentations

\begin{tabular}{lllc}
\hline Physical parameter & Measuring device & Model & Uncertainty \\
\hline Air flowrate & Differential pressure transducer & Comefri Electronic Cometer & $\pm 5 \%$ \\
Dry bulb temperature & Thermo-hygrometer & Siemens QFM3160D & $\pm 0.6{ }^{\circ} \mathrm{C}$ \\
Relative humidity & Thermo-hygrometer & Siemens QFM3160D & $\pm 4 \%$ \\
Water flowrate & Electromagnetic flow meter & Riels VMZ Series & $\pm 5 \%$ \\
Water temperature & Resistance thermometer & RTD-Pt100 & $\pm 0.15^{\circ} \mathrm{C}$ \\
$\begin{array}{l}\text { Surface electrical resis- } \\
\text { tor temperature }\end{array}$ & Resistance thermometer & RTD-Pt100 & $\pm 0.15^{\circ} \mathrm{C}$ \\
\hline
\end{tabular}

The heat power transferred to the air is a function of the enthalpy variation between inlet and outlet:

$\dot{Q}=\dot{m}_{\mathrm{da}}\left(i_{\text {air,out }}-i_{\text {air,in }}\right)$

Similarly, the evaporated water flowrate is calculated by the absolute humidity variation between inlet and outlet:

$\dot{m}_{\text {water,evap }}=\dot{m}_{\mathrm{da}}\left(x_{\text {air,out }}-x_{\text {air,in }}\right)$

\section{Results and discussion}

The influence of relative humidity was analyzed, according to the variation in the setpoint value in the range 50-90\%, leaving the remaining parameters unchanged, as summarized in Table 3 (Case A). The values reported in the following tables are referred to the $\mathrm{RH}_{\text {setpoint }}$ that is the setpoint of the air exiting from the AHU (as reported in Fig. 1) that is different from the actual values measured just before the tubes, as air meets the water that increases its humidity through the channel to the measuring section. The value reported in the table as $\mathrm{RH}_{\text {setpoint }}$ is that chosen by the operator for the $\mathrm{TH}_{1}$ sensor in Fig. 1, while the values $\mathrm{RH}_{\mathrm{in}}$, reported in the graph in Fig. 4,

Figures 5-9, are those measured by the sensor $\mathrm{TH}_{2}$, as reported in the scheme in Fig. 1.

The average values of heat transfer rate, depending on the relative humidity measured before the electrical heaters, are reported in Fig. 4.

Table 3 Test operating conditions (Case A)
The dissipated heat power decreases with the increase in the relative humidity as the latent contribution to the total heat transfer rate is reduced. This decrease accounts for the fact that the latent heat transfer driver is the difference between the partial pressure of the vapor between adjacent air layers close to the tubes wall.

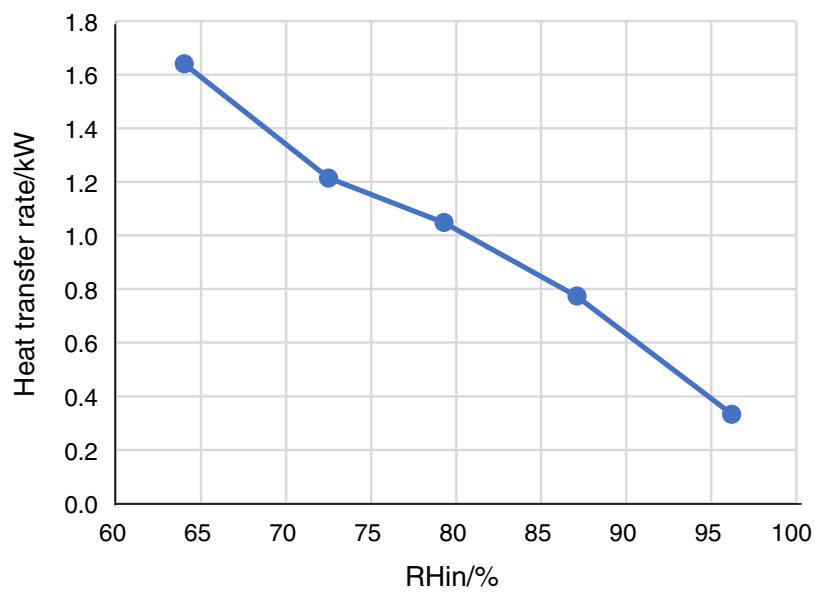

Fig. 4 Heat transfer rate trend vs relative humidity (Case A)

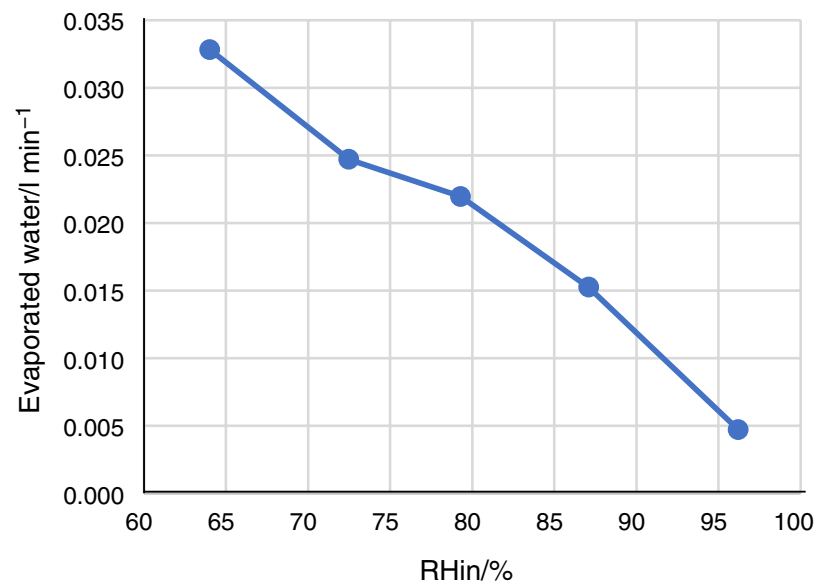

Fig. 5 Evaporated water trend with relative humidity (Case A) 
The decrease becomes more and more considerable in terms of percentage at higher humidity values. At low values of relative humidity, an $8 \%$ increase implies a $26 \%$ heat transfer rate decrease; at high values of relative humidity, instead, at an equal relative humidity reduction, it corresponds a $57 \%$ heat power reduction. The slope of the tendency is almost regular in the range of the evaluated $\mathrm{RH}$. In Fig. 4 , it is also clear that between 70 and $80 \%$ of relative humidity, there is a light change in the slope.

As shown in Fig. 5, the amount of evaporated water is reduced by $89 \%$, when at the inlet the relative humidity increases from 64 to $96 \%$. It is evident from this figure that between 70 and $80 \%$ of relative humidity, a similar behavior of a light change in the slope of the curve can be observed as in Fig. 4.

The combined effect of dry bulb temperature and relative humidity on the performance of the evaporative condenser has been then evaluated. The tests were carried out for three dry bulb temperature levels and five humidity levels, as shown in Table 4 (Case B), where the operating conditions are reported.

Figure 6 shows that the heat power decreases with both dry bulb temperature and relative humidity increase. For what concerns the reduction in the sensible contribution to heat transfer, it is clear that this depends on the decreased temperature difference between the tube surfaces and the air.

From Fig. 6, it can be observed that when increasing the temperature from 19 to $25{ }^{\circ} \mathrm{C}$, the heat transfer rate is reduced by $38 \%$ at a relative humidity of $79 \%$, while the same temperature difference causes a reduction of $74 \%$ at a relative humidity of around $96 \%$. In particular, the greatest decrease in the exchanged heat power occurs when the

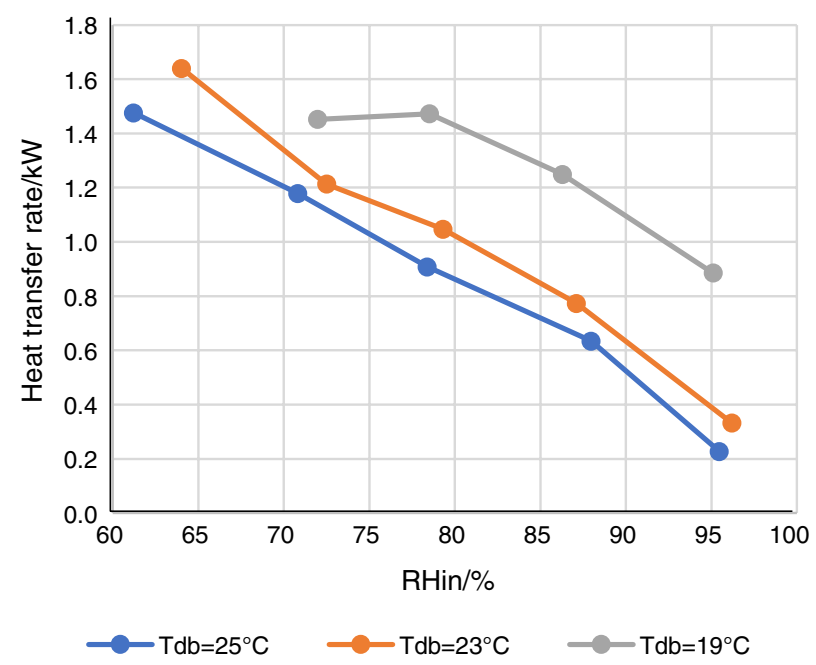

Fig. 6 Heat transfer rate trends vs relative humidity and dry bulb temperature (Case B) temperature increases from 19 to $23{ }^{\circ} \mathrm{C}$. In this situation, there is a $63 \%$ reduction in power at $96 \%$ humidity.

The test conditions carried out for three different inclinations, for a fixed dry bulb temperature as the relative humidity varies, are reported in Table 5 (Case C).

Figure 7 shows the trend of the dissipated heat power as a function of the relative humidity, for the experimental conditions reported in Table 5.

In general, it can be stated that the capacity of the system increases with the increase in the inclination of the geometry. This can be explained as such an increase causes an increase in the frontal surface of heat transfer with respect to the air flow. This is particularly true for relative humidity values between 75 and $90 \%$.

There is a $45 \%$ increase in heat transfer performance when switching from $0^{\circ}$ to $20^{\circ}$ inclined geometry at a humidity of $79 \%$, and a $39 \%$ increase in the heat power exchanged at a relative humidity value of $87 \%$.

When switching to humidity values outside the range $75-90 \%$, the curves of heat power tend to overlap and the influence of the inclination becomes less significant. The average increase is about $27 \%$.

After evaluating the main effects of the variations in the test conditions on the heat transfer performance, the results obtained with the circular geometry are compared with those obtained with the elliptical section exchange geometry, evaluating the percentage increases in dissipated heat power and

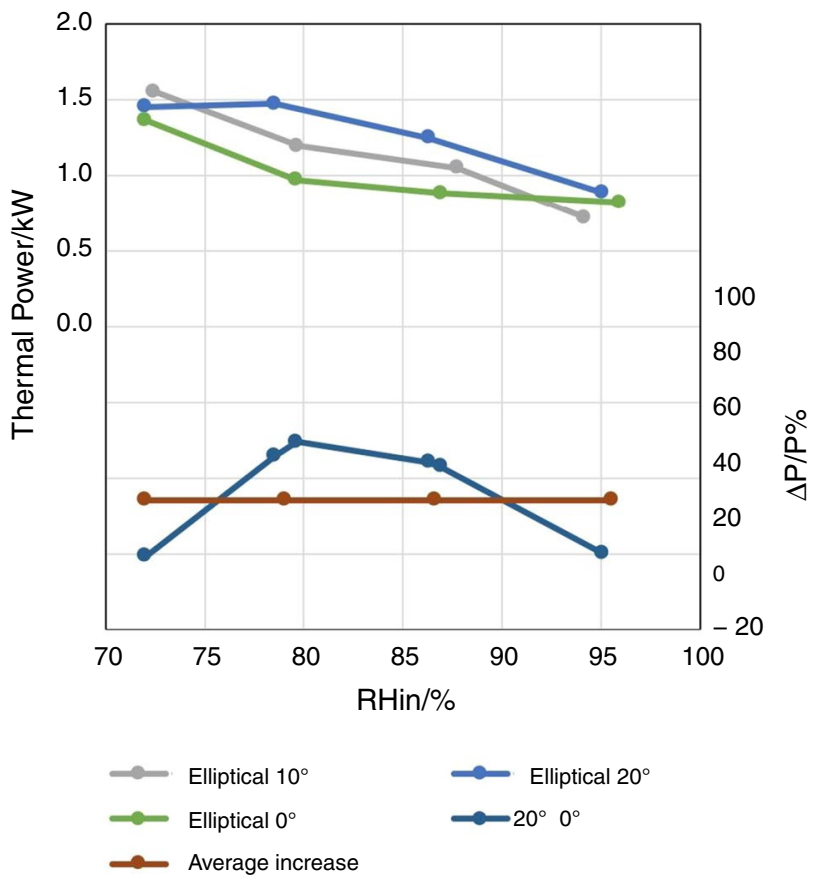

Fig. 7 Heat power vs relative humidity and different inclinations (Case C) 


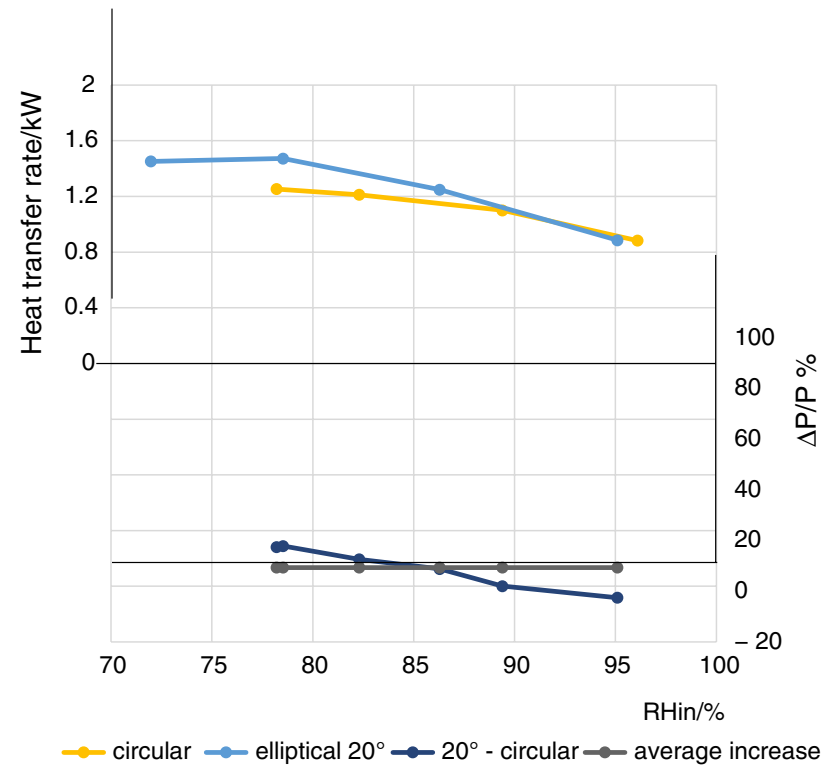

Fig. 8 Heat transfer rate and percentage increase trend comparison vs relative humidity between circular and elliptical tubes

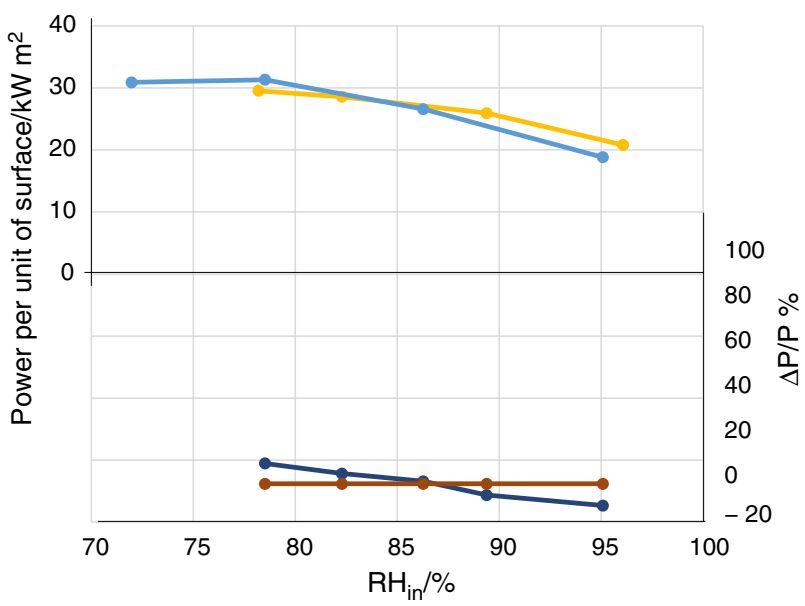

$\rightarrow$ circular $\rightarrow$ elliptical $20^{\circ} \rightarrow-20^{\circ}$ - circular $\rightarrow$ average increase

Fig. 9 Heat transfer rate per unit area and percentage increase trend comparison vs relative humidity between circular and elliptical tubes

Table 4 Test operating conditions (Case B)
Table 5 Test operating conditions (Case $\mathrm{C}$ )

Table 6 Test operating conditions (Case D)

heat power per unit area, passing from the first to the second geometry.

Given, as seen, that the highest performance for elliptical tubes occurs as their inclination increases with respect to the main axis, for comparison with circular tubes, the results of the inclinations at $20^{\circ}$ for this geometry have been taken into consideration. The operating conditions are summarized in Table 6 (Case D).

Figure 8 shows the trend of the heat transfer as a function of the inclination and of the elliptical tubes and, on the right secondary vertical axis, the percentage increase in the heat power. The graph shows how the transition from pipes with circular section to pipes with elliptical section involves an average increase in heat transferred of about $9.5 \%$. The average variation decreases with the increase in the relative humidity; actually, for relative humidity of $95 \%$, the transition from a configuration of tubes with circular section to an elliptical section involves a reduction of $2.5 \%$ of the dissipated heat. This is likely due to the influence of the highest inclination the velocity and pressure field that locally counteracts the heat transfer surface increase with fluid dynamic effects resulting in a reduced overall convection heat transfer coefficient.

The two geometries were compared then also in terms of heat power dissipation per unit area. Figure 9 shows how, moving from the configuration of tubes with a circular section to a geometry with an elliptical section inclined by $20^{\circ}$ with respect to the major axis, the heat power per unit area decreases on average by $3 \%$, with a reduction peak of about $12.7 \%$. recorded at $95 \%$ of relative humidity.

The results of the experimental campaign show the behavior of the elliptical tubes vs circular tubes varying the 
major axis inclination in the range $0^{\circ}-20^{\circ}$. The experimental data show that even in the presence of a reduced heat transfer coefficient at the air side, the elliptical geometry has an advantage versus the circular one in terms of heat transfer values and this increase is amplified at an inclination of $20^{\circ}$ of the major axis that is the optimal arrangement obtained in this experimental campaign. These results would be useful for future development and research and would help in the design of new evaporative condensers that would increase performance and efficiency of refrigeration systems changing tubes geometries after overcoming manufacturing problems arising from facing with non-circular cross sections.

\section{Conclusions}

In this paper, a sensitivity analysis at the air side heat and mass transfer phenomena occurring in evaporative condenser was presented, based on an experimental campaign. A test bench, already tested and validated in previous works, was purposely designed in order to control all the parameters affecting the system performance.

An air handling unit supplying moist air to the test section allows to control air flowrate, temperature and relative humidity. In the test chamber, electrical heaters were placed to simulate at a tube scale the real geometry and the actual condensing refrigerant conditions by keeping constant at the desired values their outer surface temperatures. During the experimental campaign, the temperature of electrical heaters and air flow rate was kept at fixed values, while the influence of the other parameters was analyzed.

Analysis of the results confirms that the highest values of heat transfer correspond to low humidity and dry bulb temperature conditions. The exchanged heat powers are always higher for increasing inclinations, because of the greater frontal exchange area compared to the air flow. It must be considered, however, that with an increase in the frontal surface exposed directly to the air as a result of the increase in inclination, an increase in pressure drop has to be expected for sure. The average increase in dissipated heat power is $28 \%$ going from $0^{\circ}$ to $20^{\circ}$ of inclination.

At low relative humidity, the dissipated heat power is greater for elliptical tubes, while at high relative humidity, the dissipated heat power is greater for circular tubes that were here compared with the same staggered configuration. In any case, the total power and the power per unit area trends for the elliptical geometry have a greater slope than those for the circular geometry. In the comparison between the geometries, passing from the circular to the elliptical geometry, there is an average increase of $9.5 \%$ in the transferred heat power and an average decrease of $3 \%$ in the power per unit area. In order to have a complete picture of the influence of all the quantities participating in the heat transfer, future experimental campaigns may have as their object of investigation the influence of the air flow, the flow of water and its temperature, possibly repeating the tests for even greater inclinations.

Acknowledgements This research received co-funding from Decsa srl—Strada Cappelletta, 1-27058 Voghera (PV), Italy.

Funding Open access funding provided by Università del Salento within the CRUI-CARE Agreement.

Open Access This article is licensed under a Creative Commons Attribution 4.0 International License, which permits use, sharing, adaptation, distribution and reproduction in any medium or format, as long as you give appropriate credit to the original author(s) and the source, provide a link to the Creative Commons licence, and indicate if changes were made. The images or other third party material in this article are included in the article's Creative Commons licence, unless indicated otherwise in a credit line to the material. If material is not included in the article's Creative Commons licence and your intended use is not permitted by statutory regulation or exceeds the permitted use, you will need to obtain permission directly from the copyright holder. To view a copy of this licence, visit http://creativecommons.org/licenses/by/4.0/.

\section{References}

1. Ahmadi MH, Ahmadi MA. Thermodynamic analysis and optimization of an irreversible Ericsson cryogenic refrigerator cycle. Energy Convers Mange. 2015;89:147-55.

2. Ahmadi MH, Ahmadi MA, Sadatsakkak SA. Thermodynamic analysis and performance optimization of irreversible Carnot refrigerator by using multi-objective evolutionary algorithms (MOEAs). Renew Sust Energy Rev. 2015;51:1055-70.

3. Mohammadi A, Kasaeian A, Pourfayaz F, Ahmadi MH. Thermodynamic analysis of a combined gas turbine, ORC cycle and absorption refrigeration for a CCHP system. Appl Therm Eng. 2017;111:397-406.

4. Bykov AV, Gogolin VA, Tovaras NV. Investigation of heat, mass transfer and fluid flow characteristics in evaporative condensers. Int J Refrig. 1984;7(6):342-7.

5. Webb RL. A unified theoretical treatment for thermal analysis of cooling towers, evaporative condensers and fluid coolers. Conf ASHRAE Trans. 1984;90(2):398-415.

6. Qureshi BA, Zubair SM. The impact of fouling on performance evaluation of evaporative coolers and condensers. Int J Energy Res. 2005;29(14):1313-30.

7. Qureshi BA, Zubair SM. A comprehensive design and rating study of evaporative coolers and condensers Part I Performance evaluation. Int J Refrig. 2006;29(4):645-58.

8. Acunha IC Jr, Schneider PS. Numerical simulation of air-water flows in an evaporative condenser. Therm Eng. 2009;8(1):24-30.

9. Jahangeer KA, Tay AAO, Islam MR. Numerical investigation of transfer coefficients of an evaporatively-cooled condenser. Appl Therm Eng. 2011;31(10):1655-63.

10. Rashidi S, Mahian O, Languri EM. Applications of nanofluids in condensing and evaporating systems. J Therm Anal Calorim. 2018;131:2027-39.

11. Fiorentino M, Starace G. A numerical model to investigate evaporative condensers behaviour at tube scale. In: ASME 2014 12th Biennial Conference on Engineering Systems Design and 
Analysis. American Society of Mechanical Engineers; 2014. V003T12A015-V003T12A015.

12. Fiorentino M, Starace G. Numerical investigations on twophase flow modes in evaporative condensers. Appl Therm Eng. 2016;94:777-85.

13. Leidenfrost W, Korenic B. Analysis of evaporative cooling and enhancement of condenser efficiency and of coefficient of performance. Heat Mass Transf. 1979;12(1):5-23.

14. Leidenfrost W, Korenic B. Evaporative cooling and heat transfer augmentation related to reduced condenser temperatures. Heat Transf Eng. 1982;3(3-4):38-59.

15. Nasr MM, Hassan MS. Experimental and theoretical investigation of an innovative evaporative condenser for residential refrigerator. Rene Energy. 2009;34(11):2447-54.

16. Tissot J, Boulet P, Trinquet F, Fournaison L, Lejeune M, Liaudet F. Improved energy performance of a refrigerating machine using water spray upstream of the condenser. Int J Refrig. 2014;38:93-105.

17. Islam MR, Jahangeer KA, Chua KJ. Experimental and numerical study of an evaporatively-cooled condenser of air-conditioning systems. Energy. 2015;87:390-9.

18. Ettouney HM, El-Dessouky HT, Bouhamra W, Al-Azmi B. Performance of evaporative condensers. Heat Trans Eng. 2001;22(4):41-55.

19. Hajidavalloo E, Eghtedari H. Performance improvement of aircooled refrigeration system by using evaporatively cooled air condenser. Int J Refrig. 2010;33(5):982-8.

20. Liu H, Zhou Q, Liu Y, Wang P, Wang D. Experimental study on cooling performance of air conditioning system with dual independent evaporative condenser. Int J Refrig. 2015;55:85-92.

21. Junior ICA, Smith-Schneider P. Consolidated experimental heat and mass transfer database for a reduced scale evaporative condenser. Int J Refrig. 2016;66:21-31.

22. Brodnianska Z, Kotsmid S. Numerical study of heated tube arrays in the laminar free convection heat transfer. Energies. 2020; 13(4): art. no. en 13040973.

23. Adam AY, Oumer AN, Najafi G, Ishak M, Firdaus M, Aklilu TB. State of the art on flow and heat transfer performance of compact fin-and-tube heat exchangers. J Therm Anal Calorim. 2020;139:2739-68.

24. Moalem D, Sideman S. Theoretical analysis of a horizontal condenser-evaporator elliptical tube. J Heat Trans. 1975;97(3):352-9.

25. Zhang L, Yang S, Xu H. Experimental study on condensation heat transfer characteristics of steam on horizontal twisted elliptical tubes. Appl Energy. 2012;97:881-7.

26. Janjua MM, Khan NU, Khan WA, Khan WS, Ali HM. Numerical study of forced convection heat transfer across a cylinder with various cross sections. J Therm Anal Calorim. 2020;143(3):2039-52.
27. Yang SA, Chen CK. Transient film condensation on a horizontal elliptical tube. J Physics D: Appl Physics. 1993;26(5):793-7.

28. Indurain B, Uystepruyst D, Beaubert F, Lalot S, Helgadóttir Á. Numerical investigation of several twisted tubes with non-conventional tube cross sections on heat transfer and pressure drop. J Therm Anal Calorim. 2020;140(3):1555-68.

29. Sharma JP, Sharma A, Jilte RD, Kumar R, Ahmadi MH. A study on thermohydraulic characteristics of fluid flow through microchannels. J Therm Anal Calorim. 2020;140:1-32.

30. Aghayari R, Maddah H, Pourkiaei SM, Ahmadi MH, Chen L, Ghazvini M. Theoretical and experimental studies of heat transfer in a double-pipe heat exchanger equipped with twisted tape and nanofluid, Europ. Phys J Plus. 2020;135(2):252.

31. Payambarpour SA, Alhuyi Nazari M, Ahmadi MH, Chamkha AJ. Effect of partially wet-surface condition on the performance of fin-tube heat exchanger. Int J Num Meth Heat Fluid Flow. 2019;29(10):3938-58.

32. Payambarpour SA, Shokouhmand H, Ahmadi MH, El Haj Assad M, Chen L. Effect of wetness pattern on the fin-tube heat exchanger performance under partially wet-surface condition. Therm Sci Eng Prog. 2020;19:100619.

33. Fiorentino M, Starace G. Numerical and experimental performance analysis of evaporative condensers. Energy Proc. 2016;101:26-33.

34. Fiorentino M, Starace G. Experimental investigations on evaporative condensers performance. Energy Proc. 2017;140:458-66.

35. Fiorentino M, Starace G. Experimental investigations on air side heat and mass transfer phenomena in evaporative condensers. Int J Heat Technol. 2017;35(1):S399-404.

36. Fiorentino M, Starace G. Sensitivity analysis of evaporative condensers performance using an experimental approach. Energy Proc. 2017; 126:345-52.

37. Starace G, Fiorentino M, Longo MP, Carluccio E. A hybrid method for the cross flow compact heat exchangers design. Appl Therm Eng. 2017;111:1129-42.

38. Fiorentino M, Starace G. The design of countercurrent evaporative condensers with the hybrid method. Appl Therm Eng J. 2018;130:889-98.

39. Hugo Hens SLC. Building physics - heat, air and moisture: fundamentals and engineering methods with examples and exercises. KG: Wilhelm ernst \& sohn Verlag für Architektur und technische Wissenschaften GmbH \& Co; 2017.

Publisher's Note Springer Nature remains neutral with regard to jurisdictional claims in published maps and institutional affiliations. 